\title{
On competing degree morphemes in verbs of change in Southern Aymara ${ }^{1}$ Gabriel MARTÍNEZ VERA - University of Connecticut
}

\begin{abstract}
In this paper, I address verbal predicates of change in Southern Aymara, an understudied Andean language. I concentrate on verbs that are derived with the suffix -cha. This suffix derives degree achievements and creation predicates. I propose that they should be analyzed uniformly as degree achievements. The main empirical point of this paper is that there are two degree morphemes that combine with verbs with -cha, namely, a covert positive morpheme $v$.POS and an overt suffix $-s u$. The latter is a degree morpheme that restricts the standard of comparison to lexical or contextual maximal degrees. I propose an analysis in terms of Maximize Presupposition: $v$.POS and -su constitute lexical alternatives where the latter is preferred over the former when maximal values are reached. $v$.POS is thus felicitous when no maximum is reached. The discussion bears on how telicity is achieved cross-linguistically when degree achievements are considered, thus enriching our typologies on the topic.
\end{abstract}

Keywords: degree achievement, creation predicate, telicity, Maximize Presupposition, Aymara.

\section{Introduction}

This paper addresses the compositional semantics of morphologically derived verbs of change in Southern Aymara (henceforth, Aymara). Aymara is an understudied Andean language spoken in southern Peru, Bolivia and northern Chile. Typologically, Aymara is a suffixal and to some extent agglutinative language whose sentences have an SOV order. In particular, I concentrate on the the Peruvian variety of the town of Pomata (province of Chicuito, department of Puno) that is spoken by 13,637 people (Instituto Nacional de Estadística e Informática, 2010).

In particular, I concentrate on verbal predicates of change that are derived by means of the suffix -cha. This suffix derives two kinds of predicates, i.e., degree achievements and creation predicates, as shown in the examples in (1) and (2) respectively:2,3,4

\footnotetext{
${ }^{1}$ I would like to especially thank Jon Gajewski for extensive discussion on this topic. His constant feedback has been invaluable in the development of this project. I would also like to thank Roger Gonzalo Segura for discussing particular points of the Aymara grammar with me, in particular, for clarifying several aspects of what the sentences included in this paper may or may not mean. I would also like to thank Magda Kaufmann, Stefan Kaufmann and Jonathan Bobaljik for comments on previous drafts. Many ideas that I adopted in the end are the result of their feedback. Thanks also to Karlos Arregi, Itamar Francez, Chris Kennedy, Angelika Kratzer, Manfred Krifka and Lisa Matthewson for discussion and suggestions at different stages of the project. This work was supported by NSF IGERT DGE-1144399 to the University of Connecticut, the University of Connecticut's CT IBACS 2016 and the University of Connecticut's El Instituto's Tinker Award 2016-2017.

${ }^{2}$ Abbreviations: $3=$ third person, $\mathrm{ABL}=$ ablative, $\mathrm{ACC}=$ accusative, $\mathrm{EVI}=$ evidential, $\mathrm{S}=$ subject, $\mathrm{TOP}=$ topic.

${ }^{3}$ I put elided vowels in parentheses.

${ }^{4}$ I translate the examples in the past, as this is the default way native speakers understand the sentences I discuss (Aymara does not distinguish present and past). In addition, in Aymara, there are no determiners, so bare nouns could be understood as definite or indefinite. In what follows, all the arguments (subjects and objects) should be understood as singular and definite (for this reason, I glossed them with the definite determiner). I leave aside the contribution of the so-called evidential -wa.
} 
(1)
a. Mariya ñik'ut(a)- $\emptyset$ llusk'a-ch(a)-i-wa.
Mariya hair-ACC straight-cha-3S-EVI
'Mary straightened the hair.'
b. Mariya mis(a)- $\emptyset$ q'añu-ch(a)-i-wa.
Mary table-ACC dirty-cha-3S-EVI
'Mary dirtied the table.'
(2) Jaqi uka thak(i)- $\emptyset$ thaki-ch(a)-i-wa. person that path-ACC path-cha-3S-EVI 'The people built that path.'

The sentences in (1) illustrate degree achievements with -cha with the verbs llusk'a-cha-ña

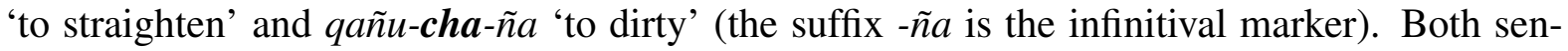
tences are similar to their English counterparts in the glosses in that they mean that the theme increases in their degree along the scale associated with the base predicates, i.e., the scale of straightness and dirtiness in the examples. In addition, -cha derives verbs creation predicates like thaki-cha-ña 'to build (path-like things)' in (2). This sentence means that an object, here a path, comes into existence. In this paper, I provide evidence that suggests that these two different kinds of verbal predicates should be analyzed in the same way in the Aymara case under discussion. Specifically, I argue that they should be analyzed as degree achievements in the sense of Kennedy and Levin (2008), i.e., in terms of an increase along a scale.

The main contribution of this paper regards how telicity contrasts are achieved in expressions including verbs with -cha. For instance, the English translation in (1a) and (2) have a default telic reading. (1a) has a default absolute reading in which a culmination is reached, i.e., the theme is straightened to its maximum (= a maximal degree of straightness is reached), so telic adverbials are preferred over atelic ones. The same can be said with regard to (2): this sentence has a default reading in which the building of the theme reaches a point in which it is fully built, so the distribution of adverbials is the same as for (1a). (1b), on the other hand, shows a different behavior: since the scale of dirtiness does not have a lexical maximum, culmination is not implied, which further means that atelic adverbials are preferred over telic ones.

Aymara is different in this regard. The sentences in (1) and (2) behave identically in that they are all understood in terms of the lack of a culmination, so atelic adverbials are preferred over telic ones. For a culmination to be reached, another suffix needs to be attached. This suffix is -su. The sentences in (1) and (2) are repeated below including -su now. In this case, then, telic adverbials are acceptable, but atelic ones are not. In other words, telicity contrasts in Aymara verbs derived with -cha depend on the presence or absence of $-s u$.
a. Mariya ñik'ut(a)- $\emptyset$ llusk'a-ch(a)-su-(i)-wa.
Mariya hair-ACC straight-cha-su-3S-EVI
'Mary straightened the hair (to a lexical maximal degree).'
b. Mariya mis(a) q'añu-ch(a)-su-(i)-wa.
Mary table-ACC dirty-cha-su-3 S-EVI
'Mary dirtied the table (to a contextual maximal degree).' 
(4)
Jaqi uka ut(a)- $\emptyset$ uta-ch(a)-su-(i)-wa.
person that house-ACC house-cha-su-3S-EVI
'The people built that house (and finished it).'

I propose an analysis in terms of Maximize Presupposition Heim (1991): assuming Kennedy and Levin's (2008) account of degree achievements, I argue that Aymara has two degree morphemes, a covert verbal positive morpheme v.POS and -su, which are lexical alternatives. -su restricts the standard to maximal values; v.POS shows no restrictions in this regard. Since -su has a restricted domain, it is preferred over $v$. POS whenever a maximum is reached. This derives the contrast in telicity between Aymara and English, which in turn enriches our typologies regarding how telicity is achieved cross-linguistically. I thus provide evidence from Aymara for a so far unattested two degree morpheme system in connection with scalar verbs of change.

The data discussed in this paper are based on two sources of information: grammatical descriptions, in particular, Cerrón-Palomino (2008) and Gonzalo Segura (2011), and original fieldwork with two consultants. The methodology used for the latter involved the presentation of contextual scenarios using Spanish as an auxiliary language, which was followed by a request for a felicity judgment on a particular grammatical sentence given that contextual scenario. I refer the reader to Bochnak and Matthewson (2015), Davis et al. (2014), Matthewson (2004) for discussion regarding the soundness and validity of the aforementioned methodological choices.

The paper is organized as follows; in section 2, I discuss verbs with -cha, including what base predicates it takes, and why degree achievements and creation predicates should be analyzed in the same way in this case. In section 3, I add -su into the discussion, addressing the telicity contrasts it gives rise to. In section 4, I provide an account of the facts discussed and address the predictions of the analysis. In section 5, I summarize the main points of the discussion.

\section{Verbs with -cha}

In this section, I address derived verbs with - cha. In subsection 2.1, I discuss the meanings verbs with -cha can have and argue that they should be analyzed uniformly. In subsection 2.2, I discuss what base predicates -cha takes.

\subsection{Degree achievements and creation predicates brought together}

The suffix -cha derives degree achievements (5) and creation predicates (6). ${ }^{5}$ The sentences in (5) mean that the theme uta 'the house' increases in the extent to which it is beautified (5a) or strengthened (literally, hardened) (5b). The sentence in (6) means that an object, uta 'the house' in this case, comes into existence - the verb uta-cha-ña is thus a creation predicate. This verb is used to mean that any house-like thing is built (e.g., schools, offices, buildings, etc.).

a. Mariya ut(a)- $\emptyset \quad$ k'acha/t'ika-ch(a)-i-wa.

Mary house-ACC beautiful/ornament-cha-3S-EVI

${ }^{5}$ I set aside the contribution of the external argument. 
'Mary beautified the house.'

b. Jaqi ut(a)- $\emptyset$ qala-ch(a)-i-wa.

person house-ACC stone/hard-cha-3S-EVI

'The people strengthened the house.'

$$
\begin{aligned}
& \text { Jaqi uka ut(a)- } \emptyset \text { uta-ch(a)-i-wa. } \\
& \text { person that house-ACC house-cha-3S-EVI } \\
& \text { 'The people built that house.' }
\end{aligned}
$$

The sentences in (5) and (6) further show that - cha takes non-gradable and gradable bases. (5a) includes two derived verbs that mean the same, i.e., 'beautify'. Their bases are k'acha 'beautiful', which is gradable, and t'ika 'ornament', which is non-gradable. (5b) includes a derived verb whose base, qala, is ambiguous between a non-gradable version meaning 'stone' and a gradable version meaning 'hard'. The verb with -cha, however, can only mean 'to harden'. (6) includes a verb derived from the non-gradable base uta 'house'.

In what follows, I propose that degree achievement readings and creation predicate readings are to be analyzed uniformly when verbs with - cha are considered, specifically, they should be analyzed together as degree achievements (in the sense of Kennedy and Levin 2008; see section 4 for the proposal) involving gradable bases. I provide three pieces of evidence that suggest that a unified analysis should be pursued.

First, both degree achievements and, crucially, creation predicates can be modified by adverbial intensifiers, such as sinti 'a lot', sinti-puni 'too much' and juk'aki 'a little'. The claim is that if these modifiers are grammatical, the predicates involved are gradable, in this case, involving a degree achievement-like reading (see Kennedy 2012 for discussion). This is illustrated in (7).

$$
\begin{aligned}
& \text { a. Mariya sinti / sinti-puni / juk'aki ut(a)- } \emptyset \text { k'acha/t'ika-ch(a)-i-wa. } \\
& \text { Mary a.lot / too.much / a.little house-ACC beautiful/ornament-cha-3S-EVI } \\
& \text { 'Mary beautified the house a lot/too much/a little.' } \\
& \text { b. Jaqi sinti / sinti-puni / juk'aki uka ut(a)- } \emptyset \text { uta-ch(a)-i-wa. } \\
& \text { person a.lot / too.much / a.little that house-ACC house-cha-3S-EVI } \\
& \text { 'There was a lot/too much/a little of the people's building of that house.' } \\
& \text { Lit. 'The people built that house a lot/too much/a little.' }
\end{aligned}
$$

Second, consider the pair of sentences in (5a) with the verbs k'acha-cha-ña and t'ika-cha-ña 'to beautify' with gradable $k$ 'acha 'beautiful' and non-gradable t'ika 'ornament' respectively. Interestingly, as suggested by means of the same gloss in the examples, sentences with these verbs appear to have rather similar meanings-in particular, the verb with non-gradable $t$ ' $i k a$ 'ornament' has the marks of property predication, just like the verb with gradable $k$ ' $a c h a$ 'beautiful'. For instance, they are both felicitous if any improvement that beautifies uta 'the house' is made, e.g., by painting it or remodeling it. Note that this is not tied to actually putting ornaments in the theme, which is the literal meaning of $t^{\prime} i k a$ 'ornament'. Another context in which these verbs can be used is shown in (8), where Susi is made more beautiful, e.g., by getting a new haircut or a new piece of jewelry. Of relevance here is thus the idea of making the theme (more) beautiful-i.e., the degree achievement reading. 


\author{
Mariya ut(a)- $\emptyset \quad$ / Sus(i)- $\emptyset \quad$ k'acha/t'ika-ch(a)-i-wa. \\ Mary house-ACC / Susi-ACC beautiful/ornament-cha-3S-EVI \\ 'Mary beautified the house/Susi.'
}

Third, consider the sentence in (5b) with the verb qala-cha-na 'to harden'. The base predicate is the ambiguous qala 'stone, hard'. Interestingly, the verb can only mean 'to harden' (not 'to turn into stones' or 'to create stones'). Thus, for instance, (5b), repeated below, is felicitous when the structures of the theme are strengthened, and, crucially, stones need not be involvedany strengthening will make (9) felicitous. In addition, targeting the non-gradable meaning is infelicitous: imagine a context in which a god turns things into stones. In this scenario, a sentence with qala-cha-na 'to harden' is infelicitous. This suggests that only the degree achievement reading (i.e., the verb with the gradable base) is available in this case.

$$
\begin{aligned}
& \text { Jaqi ut(a)- } \emptyset \quad \text { qala-ch(a)-i-wa. } \\
& \text { person house-ACC stone/hard-cha-3s-EVI } \\
& \text { 'The people strengthened the house.' }
\end{aligned}
$$

Based on these pieces of evidence, I propose that degree achievements and creation predicates in Aymara should be analyzed uniformly. In particular, in this paper I adopt the view that they should all be analyzed as degree achievements (in the sense of Kennedy and Levin 2008), being derived from a gradable base. I now turn to the distribution of the latter in verbs with -cha.

\title{
2.2. Base predicates
}

Following extensive literature on the topic (Cresswell, 1976; Kennedy and McNally, 2005; Klein, 1991; Pedersen, 2015), gradable base predicates can be characterized in terms of scales $S$, which are sets of linearly ordered degrees $d$ along some dimension associated with a base predicate. A scale $S$ is defined as follows:

(10) The scale $S$ associated with a gradable base predicate is a pairing $\langle S,<\rangle$ or $\langle S,>\rangle$, where $<$ or $>$ is a linear order on $S$.

The minimal and maximal degrees in the scale $S$ of a gradable base predicate are defined in (11) - note that if $\min$ or $\max$ exists, it is unique (since the scale is linearly ordered):

(11) a. $\min$, the minimal degree $\in S$, is defined as the degree $d$ such that no degree $d^{\prime}<d$.

b. max, the maximal degree $\in S$, is defined as the degree $d$ such that no degree $d<d^{\prime}$.

The scale associated with a predicate could have (i) no minimal or maximal degree, i.e., open scales (12a), (ii) either a minimal or a maximal degree, i.e., partially closed scales, as in (12b), or (iii) both a minimal and a maximal degree, i.e., closed scales, as in (12c). (12) illustrates the same dimensions, i.e., beauty in (12a), cleanliness/dirtiness and curliness/straightness (12b), and emptiness/fullness in (12c) but opposite orderings, as indicated in the parentheses next to each item. 

a. Open scales
ugly $\quad(>) \quad$ beautiful $(<)$
b. Partially closed scales

$\begin{array}{llll}\text { clean } & (>) & \text { dirty } & (<) \\ \text { curly } & (>) & \text { straight } & (<)\end{array}$
c. Closed scales
empty $(>) \quad$ full $\quad(<)$

Turning now to verbs with -cha, the suffix takes gradable bases with any kind of scale, as shown in (13), i.e., open scales (13a), partially closed scales (13b)-(13c) and closed scales (13d).

$\begin{array}{lllll}\text { a. k'acha } & \text { 'beautiful' } & \text { k'acka-cha-ña } & \text { 'to beautify' } \\ \text { b. q'añu } & \text { 'dirty' } & \text { qañu-cha-ña } & \text { 'to dirty' } \\ \text { c. llusk'a } & \text { 'straight' } & \text { llusk'a-cha-ña } & \text { 'to straighten' } \\ \text { d. phuqa } & \text { 'full' } & \text { phuqa-cha-ña } & \text { 'to fill' }\end{array}$

Moreover, as anticipated with regard to (5b)-(9), there is a group of bases for which there is a non-gradable and a gradable version. When the -cha verb is derived, only the gradable version of the base (whose scale is open) is used-as mentioned in subsection 2.1, targeting the nongradable meaning is infelicitous; only the gradable meaning is available in the derived verb.
a. qala
'stone, hard'
qala-cha-ña
'to harden'
b. qamaqi
'fox, witty'
qamaqi-cha-ña
'to become wittier'
c. anu
'dog, aggressive' anu-cha-ña
'to become (more) aggressive'

An additional group of bases -cha takes is shown in (15). Here the bases are non-gradable. The verb with -cha, however, does not target the actual meaning of the base, but a property (i.e., a gradable) meaning of it (see Beavers 2011). I assume that the bases are turned into gradable to combine with -cha. ${ }^{6}$ Thus, in (15a), the verb with -cha includes a property meaning 'beautiful' and, in (15b), it includes a property meaning 'cultivatedness'.
a. t'ika
'ornament'
t'ika-cha-ña
'to beautify'
b. yapu
'sown field'
yapu-cha-ña
'to cultivate, to grow'

In general, the verbs with -cha in (13)-(15) have a degree achievement-like meaning-where a gradable base with a property scale is present.

The last group of bases - cha takes are the ones that derive creation predicates, i.e., they predicate of a theme that it comes into existence. As with regard to (15), here I assume that the bases are non-gradable; when they combine with -cha, they are turned into gradable having an extent scale associated with them (see Beavers 2011). ${ }^{7}$ I further assume that these scales are top closed, i.e., there is a maximum corresponding to the actual presence of the entity denoted

\footnotetext{
${ }^{6} \mathrm{~A}$ general mechanism to turn non-gradable bases into gradable would be needed in this case. This would also be needed for (16) below. I set aside an explicit formulation of this in this paper.

${ }^{7}$ In this paper, extent scales are understood as scales involving that an entity comes into existence.
} 
by the base. The theme in these cases has to be somewhat similar to what the base means. Thus, the theme (16a) has to be house-like (i.e., it must have, let us say, four walls and a roof), and the theme in (16a) has to be path-like (i.e., it must have, let us say, a gap perhaps flanked by borders where entities can go through). ${ }^{8}$
a. uta
'house'
uta-cha-ña
'to build (house-like things)'
b. yapu 'path'
yapu-cha-ña
'to build (path-like things)'

To summarize, verbs with -cha derive two kinds of verbs, namely, degree achievements and creation predicates. The bases the suffix takes are both gradable and non-gradable. When taking the former, -cha derives degree achievements; when taking the latter, they are turned into gradable bases and -cha derives degree achievements or creation predicates. ${ }^{9}$

\section{Adding -su: telicity contrast}

In this section, I discuss how telicity contrasts are achieved in expressions including verbs with -cha. I first discuss telicity in connection with degree achievements in English, which I will use as a baseline in order to address how Aymara differs from it. As previous literature has pointed out with regard to English (see Dowty 1979; Abusch 1986; Winter 2006; Kennedy and Levin 2008), degree achievements like straighten in (17) are ambiguous between an absolute reading, where the theme reaches a maximal degree, namely, that representing a degree corresponding to fully straight - this is the default reading —, and a comparative reading where the theme ends up straighter, which is achieved when additional (e.g., contextual) cues are given:

$$
\text { Mary straightened the hair. }
$$

With degree achievements like dirty in (18), on the other hand, the comparative reading is strongly preferred, since the scale associated with the verb does not include an absolute maximal degree (see Winter 2006; Kennedy and Levin 2008 for discussion):

$$
\text { Mary dirtied the table. }
$$

This distinction has consequences when adverbial expressions targeting atelic and telic readings are considered. For sentences with verbs like straighten, telic adverbials like in an hour are preferred over atelic ones like for an hour, as shown in the contrast in (19), since the telic adverbial introduces a bound in the event, which is consistent with the presence of a maximal degree-as it constitutes a bound in the scale. This is not the case with atelic adverbials. This is shown in (19). For sentences with verbs like dirty, atelic adverbials are preferred over telic ones, since an atelic adverbial does not target a maximal degree. This is shown in (20). ${ }^{10}$

\footnotetext{
${ }^{8}$ I set aside a detailed account of what it means for a creation predicate to be analyzed as a degree achievement. See Beavers (2011), Kennedy (2012), Krifka (1998) and Piñón (2008) for relevant discussion.

${ }^{9}$ I leave the determination of details of the nature of the scale in (15)-(16) (i.e., whether it is open, partially closed or closed) for future research. I also set aside in what cases a non-gradable base derives a degree achievement or a creation predicate.

${ }^{10}$ The sentences to follow are conceived of as said out of the blue.
} 
(19) a. Mary straightened the hair in an hour.

b. ??Mary straightened the hair for an hour.

(20) a. ?Mary dirtied the table in an hour.

b. Mary dirtied the table for an hour.

When Aymara degree achievements with -cha are considered, in principle, the expectation would be that they behave as their English counterparts when it comes to the adjunction of (a)telicity adverbial expressions. However, this is not the case. To test (a)telicity, I make use of the telic adverbial mä ura-tha 'in an hour' and the atelic adverbial mä ura 'for an hour'. What distinguishes the adverbials is the ablative suffix -tha, which is present in telic adverbials, but is absent in atelic ones.

To illustrate this, I add the (a)telicity adverbials to the examples in (1) and (2) above, as shown below. What can be readily noticed is that there is no contrast with regard to (a)telicity regardless of the presence or absence of a maximum value in the scales associated with the verbs. In the case of llusk'a-cha-ña 'to straighten' in (21), there is a maximum in the scale. In the case

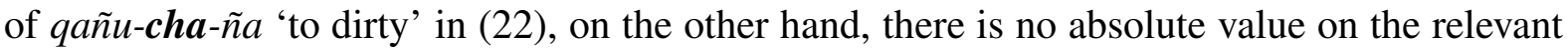
end in the scale. Despite these differences, which make English degree achievements vary with regard to (a)telicity, as shown in (19)-(20) above, the Aymara examples are consistently marked with the telic adverbial mä ura-tha 'in an hour' and consistently good with the atelic adverbial mä ura 'for an hour'. The same holds in (23) with thaki-cha-ña 'to build (path-like things)': regardless of the presence of a maximum in the scale, telic adverbials are bad and atelic ones are good.

a. ??Mariya mä ura-tha ñik'ut(a)- $\emptyset$ llusk'a-ch(a)-i-wa.

Mariya one hour-ABL hair-ACC straight-cha-3S-EVI

'Mary straightened the hair in a hour.'

b. Mariya mä ura ñik'ut(a)- $\emptyset$ llusk'a-ch(a)-i-wa.

Mariya one hour hair-ACC straight-cha-3S-EVI

'Mary straightened the hair for an hour.'

a. ??Mariya mä ura-tha mis(a)- $\emptyset$ q'añu-ch(a)-i-wa.

Mary one hour-ABL table-ACC dirty-cha-3S-EVI

'Mary dirtied the table in a hour.'

b. Mariya mä ura mis(a)- $\emptyset$ q'añu-ch(a)-i-wa.

Mary one hour table-ACC dirty-cha-3S-EVI

'Mary dirtied the table in a hour.'

a. ??Jaqi mä ura-tha uka thak(i)- $\emptyset$ thaki-ch(a)-i-wa. person one hour-ABL that path-ACC path-cha-3S-EVI

'The people built that path in an hour.'

b. Jaqi mä ura uka thak(i)- $\emptyset$ thaki-ch(a)-i-wa. person one hour that path-ACC path-cha-3S-EVI

'The people built that path for an hour.' 
For telic adverbials to be grammatical when verbs with -cha are present, the suffix -su needs to be added, as shown in (24)-(26). In grammar descriptions of Aymara, this suffix is glossed as 'completely' (see Gonzalo Segura 2011). When it is present, the judgements in (21)-(23) are reversed: telic adverbials become grammatical and atelic ones become marginal. Note in the examples that the contrast in judgment is sharp in this case: whenever -su is present, atelic adverbials become marginal. Again, it is worth emphasizing that all the sentences show the same behavior in terms of (a)telicity regardless of the presence or absence of absolute endpoint values in the scales associated with the verbs under discussion. The main contrast is thus between the presence or absence of $-s u$.
a. Mariya mä ura-tha ñik'ut(a)- $\emptyset$ llusk'a-ch(a)-su-(i)-wa. Mariya one hour-ABL hair-ACC straight-cha-su-3S-EVI
'Mary straightened the hair in a hour.'
b. ?*Mariya mä ura ñik'ut(a)-Ø llusk'a-ch(a)-su-(i)-wa.
Mariya one hour hair-ACC straight-cha-su-3S-EVI
'Mary straightened the hair for an hour.'
a. Mariya mä ura-tha mis(a)- $\emptyset$ q'añu-ch(a)-su-(i)-wa.
Mary one hour-ABL table-ACC dirty-cha-su-3S-EVI
'Mary dirtied the table in a hour.'

b. ?*Mariya mä ura mis(a)- $\emptyset$ q'añu-ch(a)-su-(i)-wa.

Mary one hour table-ACC dirty-cha-su-3S-EVI

'Mary dirtied the table in a hour.'
a. Jaqi mä ura-tha uka thak(i)- $\emptyset$ thaki-ch(a)-su-(i)-wa. person one hour-ABL that path-ACC path-cha-su-3S-EVI
'The people built that path in an hour.'
b. ?*Jaqi mä ura uka thak(i)- $\emptyset$ thaki-ch(a)-su-(i)-wa. person one hour that path-ACC path-cha-su-3S-EVI
'The people built that path for an hour.'

This discussion begs the question of what kind of element -su is. The hypothesis that I pursue in the next section is that it is a degree morpheme that targets maximal degrees.

\section{Proposal}

In this section, I propose an analysis of verbs with -cha including the telicity contrasts in connection with the presence or absence of $-s u$. Subsection 4.1 discusses the semantics I assume for verbs with -cha; subsection 4.2 argues that -su is a degree morpheme; subsection 4.3 is the analysis; subsection 4.4 discusses the predictions of the analysis.

\subsection{The semantics of derived verbs with -cha}

To account for the meanings of verbs with - cha in Aymara, my proposal is similar to Kennedy and Levin's (2008) account for English, which I briefly summarize below. The authors suggest 
that degree achievements denote a differential measure function that measures the amount that an entity changes along a scale associated with a base predicate as a result of participating in an event (see also Hay et al. 1999; Kennedy 2012; Pedersen 2015 for alternative formalizations). ${ }^{11}$ The amount mentioned corresponds to the output of the differential measure function, which equals the degree that represents the positive difference between two degrees, namely, the degree to which the theme measures the function denoted by a gradable predicate at the end of an event minus the degree to which the theme measures the function denoted by a gradable predicate at the beginning of the event; this captures the idea that there is an increase in a scale. Degree achievements are always closed on the end of the scale corresponding to this degree, i.e., there is always a derived minimum. For Kennedy and Levin (2008), the differential measure function is derived from 'regular' measure functions, i.e., those denoted by gradable predicates $m$-here I assume that gradable bases denote measure functions that map an individual and an event into a degree, where the degree is held constant in the event (Morzycki, 2015). The denotations of 'regular' and derived measure functions are shown in (27a) and (27b) respectively (Kennedy and Levin’s 2008:173):

$$
\begin{array}{ll}
\text { a. } & \llbracket \mathrm{m} \rrbracket=\lambda x \lambda e[m(x, e)] \\
\text { b. } & \text { For any measure function } m, m_{\Delta}=\lambda x \lambda e\left[m_{m(x, i n i(e))}^{\uparrow}(x, f i n(e))\right]
\end{array}
$$

I adopt this semantics for verbs with - cha, thus giving a unified semantics to degree achievements and creation predicates. My proposal differs from Kennedy and Levin's (2008) in that I suggest that, in Aymara, -cha is the lexical item that derives the differential measure functionthis follows Hay et al. (1999) and Pedersen (2015), who propose that an (abstract) suffix -en in English derives degree achievements from gradable predicates. This move seems warranted, since - cha systematically derives the verbs under discussion. The denotation of -cha appears in (28). Thus, -cha takes as arguments a measure function $m$ (a gradable predicate), an individual $x$ and an event $e$ and gives a degree that results from the difference of the degree to which $x$ measures $m$ at the end of $e$ minus the degree to which $x$ measures $m$ at the beginning of $e$. In what follows, I use the abbreviated version using $m_{\Delta}$ in (28b) (this follows Kennedy and Levin's 2008 convention in their discussion of English).

$$
\begin{aligned}
\text { a. } & \llbracket \text {-cha } \rrbracket & =\lambda m \lambda x \lambda e\left[m_{m(x, \operatorname{ini}(e))}^{\uparrow}(x, f i n(e))\right] \\
\text { b. } & \llbracket \text {-cha } \rrbracket & =\lambda m \lambda x \lambda e\left[m_{\Delta}(x, e)\right]
\end{aligned}
$$

I exemplify the proposal with the examples in (1) and (2), which are repeated in (29):

$$
\begin{aligned}
& \text { a. Mariya ñik'ut(a)- } \emptyset \text { llusk'a-ch(a)-i-wa. } \\
& \text { Mariya hair-ACC straight-cha-3S-EVI } \\
& \text { 'Mary straightened the hair.' }
\end{aligned}
$$

\footnotetext{
${ }^{11}$ Kennedy and Levin (2008:172) define the difference function as in (i) - I state it in terms of events here:

(i) For any measure function $m$ from objects $x$ and events $e$ to degrees $d$ on scale $S$, and for any $d \in S, m_{d}^{\uparrow}$ is a function just like $m$ except that:

a. its range is $\left\{d^{\prime} \in S: d \leq d^{\prime}\right\}$, and

b. for any $x, e$ in the domain of $m$, if $m(x)(e) \leq d$ then $m_{d}^{\uparrow}(x, e)=d$.
} 
b. Mariya mis(a)- $\emptyset$ q'añu-ch(a)-i-wa.

Mary table-ACC dirty-cha-3S-EVI

'Mary dirtied the table.'

c. Jaqi uka thak(i)- $\emptyset$ thaki-ch(a)-i-wa.

person that path-ACC path-cha-3S-EVI

'The people built that path.'

Restricting to the relevant part of the VPs under discussion, I assume the LF in (30) for Aymara VPs. This representation does not include degree morphology, which will be discussed in the next subsections.

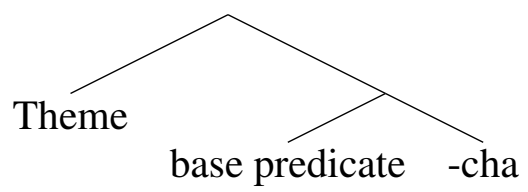

The denotations of the VPs present in (29) appear below:

$$
\begin{array}{ll}
\text { a. } & \llbracket \text {-cha } \rrbracket(\llbracket \text { llusk'a } \rrbracket)(\llbracket \text { ñikuta } \rrbracket)=\lambda e\left[\text { straight }_{\Delta}(\text { hair }, e)\right] \\
\text { b. } & \llbracket \text {-cha } \rrbracket(\llbracket \text { qañu } \rrbracket)(\llbracket \text { misa } \rrbracket)=\lambda e\left[\text { dirty }_{\Delta}\left(\text { table }_{e} e\right)\right] \\
\text { c. } & \llbracket \text {-cha } \rrbracket(\llbracket \text { thaki } \rrbracket)(\llbracket \text { uka thaki } \rrbracket)=\lambda e\left[\text { path-build }_{\Delta}(\text { that path }, e)\right]
\end{array}
$$

The denotations in (31) make explicit that there is a differential degree. This degree corresponds to the difference of the degree to which the theme measures the function denoted by the gradable base at the end of the event minus the degree to which the theme measures such function at the beginning of the event. In the examples, it is the degree to which the theme was straightened (31a), dirtied (31b) and built (31c) — this captures the idea that there has been an increase along a scale. In the next subsection, I turn to -su's status as a degree morpheme.

\section{2. $-s u$ as a degree morpheme}

In this subsection, I provide morphosyntactic evidence that suggests that $-s u$ is a degree morpheme. The claim is that $-s u$ merges very low in the structure, which is the position where degree morphemes are combined. Gonzalo Segura (2011) shows that $-s u$ is a suffix that combines very close to the verbal domain, in fact, it appears right next to -cha. It precedes all the morphemes that alter the verbal valence, such as the anticausative - $t a$ and the benefactive -rapi. It also precedes aspectual markers. For instance, the durative -ska, merges after -su-the durative also combines in the structure after the suffixes that alter the valence of the verb are combined. This distribution is consistent with $-s u$ being a degree morpheme, since this kind of elements are claimed to combine in a very low position in the structure (Hay et al., 1999; Kennedy and Levin, 2008; Pedersen, 2015).

The relative position of $-s u$ and $-s k a$ is of particular interest here, since it could be argued that -su is some kind of perfect(ive) aspectual marker, since it is closely tied to telic readings, as discussed in section 3. If -su were an aspectual marker, the prediction would be that these two 
suffixes would not co-occur-as they would head the same projection (e.g., AspectP)—, contrary to fact (see Merchant 2015 and references therein for discussion on the relative position of AspectP in the syntactic spine). in this regard, consider the example in (32), in which -su and -ska appear in the same clause. In the example, the duration of the event of Mary dirtying the table is extended, and it ends reaching a point in which it cannot be dirtied anymore. Under the hypothesis that -su targets maximal values, the presence of this suffix in (32) would mean that a (contextual) maximal degree at the end of the event is reached (as the scale associated with the base qañu 'dirty' does not include a lexical one). The English translation using the progressive tries to make explicit that the duration of the event was extended.

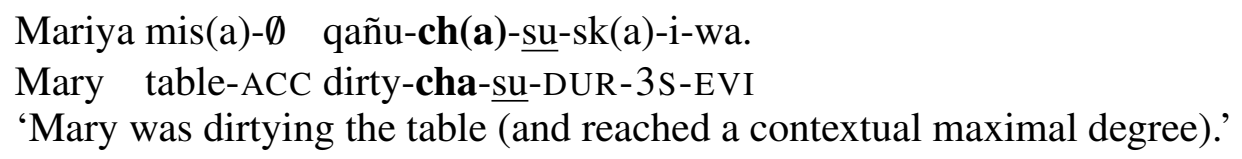

The sentence when -su is absent is also grammatical, as shown in (33). In this case, the duration of the event is also extended. Crucially, (32) and (33) differ minimally in that a maximal degree is not reached in the latter (since $-s u$ is absent). Note that in both sentences the durative's contribution to the meaning of the sentence is the same: the duration of the event is extended. Crucially, this meaning does not compete with or replace the contribution of $-s u$.

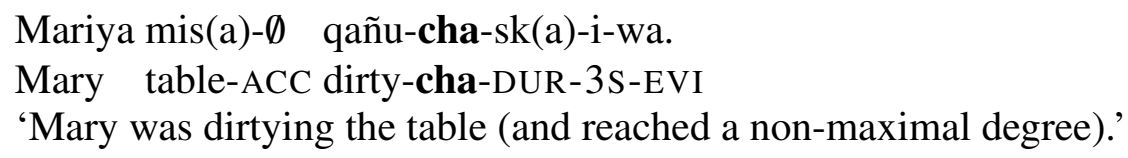

As anticipated, the relative position of the suffixes in Aymara is consistent with the proposal that $-s u$ is a degree morpheme, as it combines in a very low position in the structure (Hay et al., 1999; Kennedy and Levin, 2008; Pedersen, 2015). Based on this, I revise the LF in (30) to include degree morpheme Deg. Note that in (34) it is made explicit that Deg is combined right after the verb is formed.

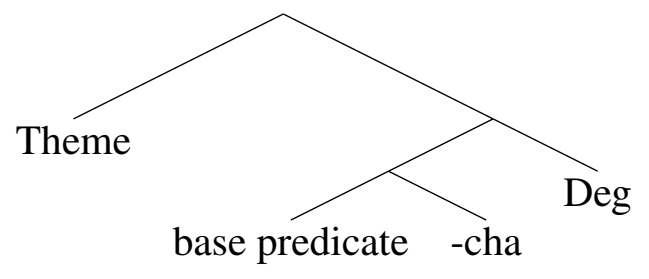

In the next subsection, I turn to the semantics of $-s u$ and discuss its relation to v.POS.

\subsection{Semantics of $-s u$ and its relation to $v . \mathrm{POS}$}

Following Kennedy and Levin (2008) (see also Pedersen 2015) in their account for English, I assume that the role of degree morphology is to turn a measure of change into a property of events. In their account, degree morphology includes a standard function, which represents the minimum degree required to stand out in a given context. Degree morphology is assumed to inherit the scalar properties of the gradable base in degree achievements relative to the kind of 
measurement encoded by the gradable base. A degree morpheme is of type $\langle\langle e, s d\rangle,\langle e, s t\rangle\rangle$ (I use $s$ for the type of events). In English, the relevant degree morphology is a verbal positive morpheme $v$.POS, which takes a derived measure of change and turns it into a property of events. Following Kennedy and Levin's (2008) convention, I use $m_{\Delta}$ as an abstract representation of derived measures of change; I also use $m_{\Delta}$ for variables of type $\langle e, s d\rangle$, which is the type of derived measures of change. (35b) says that that application of $\llbracket v \cdot P O S \rrbracket$ to $\llbracket \mathrm{m}_{\Delta} \rrbracket$ yields a function that is true of individual $x$ and event $e$ if and only if the degree of $m_{\Delta}$ (i.e., the amount to which $x$ changes in $e$ ) exceeds the minimal value or equals the maximal value of the standard of $m_{\Delta}$. To implement the assignments of values of the standard function, I propose a contextual variable assignment $g$ that assigns a value to free variables represented with index $i$ of type $d$ such that $g(i)$ is in the domain of $m_{\Delta}$ (see Barker 2002; Heim 1994; Lewis 1979; Stanley 2000).

$$
\begin{array}{ll}
\text { a. } & \llbracket v \cdot \mathrm{POS}_{i} \rrbracket^{g}=\lambda m_{\Delta} \lambda x \lambda e\left[m_{\Delta}(x, e) \geq g(i)\right] \\
\text { b. } & \llbracket v \cdot \operatorname{POS}_{i} \rrbracket^{g}\left(\llbracket \mathrm{m}_{\Delta} \rrbracket^{g}\right)=\lambda x \lambda e\left[m_{\Delta}(x, e) \geq g(i)\right]
\end{array}
$$

Kennedy and Levin (2008:169) further propose that the value of the standard function is guided by the principle of Interpretive Economy, stated below (this follows Kennedy 2007; see also Pedersen 2015):

Maximize the contribution of the conventional meanings of the elements of a sentence to the computation of its truth conditions.

There are two cases to consider, namely, when the degree achievement's scale has or does not have a lexical endpoint value-(37) repeats (17) and (18):

a. Mary straightened the hair.

b. Mary dirtied the table.

If the verb does not include a lexical endpoint value, like with dirty in (37b), there is nothing to maximize, so the value of the standard equals a derived minimum (a derived zero), i.e., the output degree of the measure function applied to the individual at the beginning of the event. Exceeding this minimum accounts for the comparative reading of degree achievements-this reading is available with all the verbs. If the degree achievement's scale does include a lexical endpoint value, like with straighten in (37a), then conventional meanings are maximized and the standard function equals the lexical maximal value in the scale. Being equal to this standard accounts for the absolute reading of degree achievements - this reading is restricted to those verbs including lexical maximal values. Interpretive Economy in (36) thus accounts for the preference of the latter reading when a degree achievement includes a lexical maximum.

Under my implementation of the standard function in terms of variable assignment $g$, the assignment of minimal or maximal values is stated as follows:
a. If $m_{\Delta}$ has a (lexical) maximal value $\max , g(i)=\max \left(m_{\Delta}\right)$.
b. If $m_{\Delta}$ does not have a (lexical) maximal value $\max , g(i)=\min \left(m_{\Delta}\right)$. 
The denotations of (37) are as shown below. The value of $g(i)$ in (39a) follows from (38a) and the value of $g(i)$ in $(39 b)$ follows from $(38 b)$.

$$
\begin{aligned}
& \text { a. } \quad \llbracket(37 \mathrm{a}) \rrbracket^{g}=\lambda e\left[\operatorname{straight}_{\Delta}(\text { hair }, e)=\max \left(\text { straight }_{\Delta}\right)\right] \\
& \text { b. } \quad \llbracket(37 \mathrm{~b}) \rrbracket^{g}=\lambda e\left[\operatorname{dirty}_{\Delta}(\text { thetable }, e)>\min \left(\operatorname{dirty}_{\Delta}\right)\right]
\end{aligned}
$$

I now turn to Aymara. Recall that I argued in section 4.1 that - cha takes a gradable base denoting a measure function and turns it into a differential differential measure one. The difference between English and Aymara lies in that in the latter there are two verbal degree morphemes, that is, in addition to verbal positive morpheme $v$. POS, there is overt $-s u$. In the spirit of Heim (1991) (see also Percus 2006), the suggestion is that the two morphemes constitute lexical alternatives LEXALT in competition, as represented in (40). While -su restricts the value of the standard to maximal ones, $v$.POS does not show any restriction, just as the English counterpart in (35a). Under the assumption that the option with a restricted domain is preferred, $-s u$ blocks $v$. POS whenever a maximum is available. The denotation of $v$.POS is repeated below for Aymara in (41a) and the denotation of -su appears in (41b). The only difference between the two lies in the domain restriction in $-s u$, where the standard equals a maximal degree. Note that this means that in Aymara Interpretive Economy need not apply in the case of the expressions under discussion, since there are additional lexical means that maximize means.

$$
\text { LEXALT }=\left\{v \cdot \operatorname{POS}_{i},-\mathrm{su}_{i}\right\}, \text { where }-\mathrm{su}_{i} \text { blocks } v \cdot \operatorname{POS}_{i} \text { if } \max \left(m_{\Delta}\right) \text { in } m_{\Delta} \text { is reached. }
$$

$$
\begin{aligned}
& \text { a. } \quad \llbracket v \cdot \mathrm{POS}_{i} \rrbracket=\lambda m_{\Delta} \lambda x \lambda e\left[m_{\Delta}(x, e) \geq g(i)\right] \\
& \text { b. } \llbracket-\mathrm{su}_{i} \rrbracket=\lambda m_{\Delta}: g(i)=\max _{i}\left(m_{\Delta}\right) \cdot \lambda x \lambda e\left[m_{\Delta}(x, e) \geq g(i)\right]
\end{aligned}
$$

In terms of what value is assigned to index $i$, in Aymara, there are three cases to consider. Two of them are similar to those that work for the English case stated in (38): if there is a lexical maximal value in the scale, it will be used (38a) and if there is no lexical maximal value in the scale, the derived minimum is used (38b), with the difference that the latter in Aymara does not show a restriction to the cases where no lexical maximal value is present-since this will be the value targeted when $v$.POS is present regardless of the presence or absence of a maximal value in the scale associated with the degree achievement. In addition to these two cases, recall that, when $-s u$ is present, another possibility is available: when the scale does not include a lexical maximal value, a contextual maximal value is used. ${ }^{12}$ The three cases are stated in (42). I distinguish lexical maximal values and contextual maximal ones by means of the notation max $^{l}$ and $\max ^{c}$ respectively.

$$
\begin{aligned}
& \text { a. If } m_{\Delta} \text { has a (lexical) maximal value } \max , g(i)=\max ^{l}\left(m_{\Delta}\right) . \\
& \text { b. If } m_{\Delta} \text { does not have a (lexical) maximal value } \max , g(i)=\max ^{c}\left(m_{\Delta}\right) \text {. } \\
& \text { c. } g(i)=\min \left(m_{\Delta}\right) .
\end{aligned}
$$

\footnotetext{
${ }^{12}$ Note that this case is not completely out in English. It is needed when a telic reading of a degree achievement without a lexical maximal degree in the scale associated with it is targeted (see Hay et al. 1999 for discussion).
} 
To illustrate the mechanics of the account, recall the examples in (29), to which I add $-s u$ :
a. Mariya ñik'ut(a)-Ø llusk'a-ch(a)-su-(i)-wa.
Mariya hair-ACC straight-cha-su-3S-EVI
'Mary straightened the hair.'
b. Mariya mis(a)- $\emptyset$ q'añu-ch(a)-su-(i)-wa.
Mary table-ACC dirty-cha-su-3S-EVI
'Mary dirtied the table.' person that path-ACC path-cha-su-3S-EVI
'The people built that path.'
c. Jaqi uka thak(i)- $\emptyset$ thaki-ch(a)-su-(i)-wa.

With regard to the sentences when $-s u$ is absent (i.e., (29)), the reasoning is as follows: they all have v.POS. In this case, the standard function could equal a minimal or a maximal value, since v.POS shows no restriction whatsoever in this regard. However, the standard will not equal a maximal degree in these cases, because there is another lexical alternative, $-s u$, which is used instead to denote that a maximal degree is reached. Thus, the standard with v.POS will equal a minimum. With regard to the sentences when $-s u$ is present, the value of the standard is specified in the denotation of $-s u$. Specifically, there is a domain restriction that explicitly states that for the sentences to be defined the standard must equal a maximal degree. In (43a) and $(43 \mathrm{c})$, the standard equals a maximal degree that is lexical, since the scales associated with the verbal predicates incorporate lexical maximal degrees. In (43b), on the other hand, the standard equals a maximal degree that is contextual, as the scale associated with the verbal predicate does not incorporate a lexical maximal degree.

The denotations of (29) and (43) appear below. The denotations of the sentences in (29) (those without $-s u$, i.e., with $v$.POS) appear in (44). Here it is made explicit that the standard equals a minimum, which falls under the assignment in (42c). These correspond with the comparative readings. The denotations in (45) are the ones of the sentences with $-s u$ in (43). Here the standard equals maximal degrees, whether lexical, as in (45a) and (45c) (this falls under the assignment in (42a)), or contextual, as in (43b) (this falls under the assignment in (42b)). These correspond with the absolute readings.

$$
\begin{array}{ll}
\text { a. } & \llbracket(29 \mathrm{a}) \rrbracket=\lambda e\left[\text { straight }_{\Delta}(\text { hair }, e)>\min \left(\text { straight }_{\Delta}\right)\right] \\
\text { b. } & \llbracket(29 \mathrm{a}) \rrbracket=\lambda e\left[\operatorname{dirty}_{\Delta}\left(\text { table }_{e}\right)>\min \left(\text { dirty }_{\Delta}\right)\right] \\
\text { c. } & \llbracket(29 \mathrm{c}) \rrbracket=\lambda e\left[\text { path-build }_{\Delta}(\text { that path }, e)>\min \left(\text { path }^{-} \text {build }_{\Delta}\right)\right]
\end{array}
$$

$$
\begin{aligned}
& \text { a. } \quad \llbracket(43 a) \rrbracket \text { is defined iff } g(i)=\max ^{l}\left(\text { straight }_{\Delta}\right) \text {. } \\
& \text { When defined, } \llbracket(43 \mathrm{a}) \rrbracket=\lambda e\left[\text { straight }_{\Delta}(\text { hair }, e)=\max ^{l}\left(\text { straight }_{\Delta}\right)\right] \\
& \text { b. } \llbracket(43 b) \rrbracket \text { is defined iff } g(i)=\max ^{c}\left(\operatorname{dirty}_{\Delta}\right) \text {. } \\
& \text { When defined, } \llbracket(43 b) \rrbracket=\lambda e\left[\operatorname{dirty}_{\Delta}(\text { table }, e)=\max ^{c}\left(\operatorname{dirty}_{\Delta}\right)\right] \\
& \text { c. } \quad \text { (43c) } \rrbracket \text { is defined iff } g(i)=\max ^{l}\left(\text { path-build }{ }_{\Delta}\right) \text {. } \\
& \text { When defined, } \llbracket(43 \mathrm{c}) \rrbracket=\lambda e\left[\text { path-build }_{\Delta}(\text { that path }, e)=\max ^{l}\left(\text { path-build }_{\Delta}\right)\right]
\end{aligned}
$$

The proposal accounts for the telicity contrast discussed in section 3. Since -su targets maximal degrees only, telic adverbials are grammatical (i.e., the absolute readings targeted in the 
presence of $-s u$ correspond with telic readings), but atelic ones are ungrammatical (when -su is present, the comparative reading is not possible). In the case of $v$. POS, the opposite holds, since the standard equals a minimum in the scale: since the comparative reading is targeted, atelic adverbials are possible, whereas telic adverbials are not.

\subsection{Predictions}

The analysis predicts that it should only be possible to combine -su with verbs that allow degree morphology. This is borne out. Consider the examples below. The examples in (46) include a lexical degree achievement: the verb ch'iyara-ña 'to darken' allows -su. The example in (47) includes pichawaya-ña 'to sweep' (an activity according to its aspectual class); here -su is not allowed.
a. Jusiya uka is(i)- $\emptyset$ ch'iyar(a)-i-wa.
Joseph this dress-ACC darken-3S-EVI
'Joseph darkened the dress to a non-maximal degree.'
b. Jusiya uka is(i)- $\emptyset$ ch'iyar(a)-su-(i)-wa.
Joseph this dress darken-su-3S-EVI
'Joseph darkened the dress to a maximal degree.'
a. Jusiya ut(a)- $\emptyset$ pichaway(a)-i-wa.
Joseph house-ACC sweep-3S-EVI
'Joseph sweeped the house.'
b. *Jusiya ut(a)- $\emptyset$ pichaway(a)-su-(i)-wa.
Joseph house-ACC sweep-su-3S-EVI
'Joseph sweeped the house to a maximal degree.'

Another interesting case to test involves the suffix $-r a$, which also derives degree achievements in Aymara. The distribution of the bases this suffix takes shows that gradable bases including a lexical maximal degree are ungrammatical. It can only take gradable bases that do not include it, as illustrated below-I set aside further differences between verbs with -cha and - $r a$ :
a. *q'amu-ra-ña
'to clean'
b. qañu-ra-ña
'to dirty'
a. *llusk'a-ra-ña
'to straighten'
b. phirqa-ra-ña
'to curl'

More generally, degree achievements with - $r$ cannot denote maximal degrees. Of particular interest here is that $-s u$ is ungrammatical with degree achievements derived with $-r a$, which is expected if -su targets maximal degrees.
a. *qañu-r(a)-su-ña
'to dirty to a (contextual) maximal degree'
b. *phirqa-r(a)-su-ña
'to curl to a (contextual) maximal degree' 
Finally, recall adverbial expressions. As discussed in subsection 2.1, verbs with -cha allow adverbial modification with elements like sinti 'a lot', sinti-puni 'too much' and juk'aki 'a little'. These elements are also possible in verbs with -cha taking -su. The expectation is that the former should be possible and the latter should be marked with sentences uttered out of the blue, since the former is compatible with high degrees, including maximal ones, whereas the latter is compatible with low (non-maximal) degrees. This prediction is borne out, as shown in $(51){ }^{13}$

Jaqi sinti / sinti-puni / ?*juk'aki uka ut(a)- $\emptyset$ uta-ch(a)-i-wa. person a.lot / too.much / a.little that house-ACC house-cha-3S-EVI

'There was a lot/too much/a little of the people's building of that house (to a maximal degree).'

\section{Conclusion}

This paper provides evidence for a two degree morpheme system combining with scalar predicates in Aymara. The suffix - cha derives degree achievements and creation predicates. I argued that they should be analyzed uniformly as degree achievements. I further discussed that telic readings correspond with the presence of the suffix $-s u$; in its absence, atelic readings are yielded. I proposed that $-s u$ is a degree morpheme that is in competition with a verbal positive morpheme $v$.POS. The former restricts the standard of comparison to maximal degrees, whereas the latter remains unrestricted. For this reason, $-s u$ is preferred over $v$.POS whenever a maximal degree is reached. Aymara then differs from English in that in the former telicity contrasts rely on the presence or absence of lexical means (i.e., of -su), whereas in the latter there is a need to resource to a pragmatic principle to maximize the lexical means that are present in the base predicate included in the verb. The Aymara system thus enriches our typology regarding how telicity is achieved cross-linguistically when scalar verbs are considered.

\section{References}

Abusch, D. (1986). Verbs of change, causation, and time. Stanford: Center for the Study of Language and Information.

Barker, C. (2002). The dynamics of vagueness. Linguistics and Philosophy 25, 1-36.

Beavers, J. (2011). On affectedness. Natural Language and Linguistic Theory 29(2), 335-370. Bochnak, M. and L. Matthewson (Eds.) (2015). Methodologies in Semantic Fieldwork. Oxford: Oxford University Press.

Cerrón-Palomino, R. (2008). Quechumara: Estructuras paralelas del quechua y del aimara. La Paz: UMSS, PROEIB Andes, Plural editores.

Cresswell, M. J. (1976). The semantics of degree. In B. Partee (Ed.), Montague Grammar, pp. 261-292. New York: Academic Press.

Davis, H., C. Gillon, and L. Matthewson (2014). How to Investigate Linguistic Diversity: Lessons from the Pacific Northwest. Language 90(4), 180-226.

\footnotetext{
${ }^{13}$ Only when it is made explicit via contextual cues that the maximal degree is very low in the scale does juk'aki 'a little' become better. This suggests that reaching a maximal degree does not necessarily mean to become a member of the positive extension of the gradable base - which is a possible case under the analysis pursued here under (42b), where a contextual maximal degree is assigned.
} 
Dowty, D. R. (1979). Word meaning and Montague grammar. Dordrecht: Kluwer.

Gonzalo Segura, R. (2011). La derivación verbal en el aimara de Pomata. Master's thesis, Pontificia Universidad Católica del Perú.

Hay, J., C. Kennedy, and B. Levin (1999). Scalar structure underlies telicity in "Degree achievements". Semantics and Linguistic Theory 9, 127-144.

Heim, I. (1991). Artikel und Definitheit. In A. v. Stechow and D. Wunderlich (Eds.), Semantik: Ein internationales Handbuch der zeitgenössischen Forschung, pp. 487-535. Berlin: Berlin de Gruyter.

Heim, I. (1994). Comments on Abusch's theory of tense. Ms., Massachusetts Institute of Technology.

Instituto Nacional de Estadística e Informática (2010). Censos de Población y Vivienda 2007.

Kennedy, C. (2007). Vagueness and grammar: The semantics of relative and absolute gradable adjectives. Linguistics and Philosophy 30(1), 1-45.

Kennedy, C. (2012). The composition of incremental change. In V. Demonte and L. McNally (Eds.), Telicity, Change, State: A Cross-Categorial View of Event Structure, pp. 103-121. New York: Oxford University Press.

Kennedy, C. and B. Levin (2008). Measure of change: The adjectival core of degree achievements. In L. McNally and C. Kennedy (Eds.), Adjectives and adverbs: Syntax, semantics and discourse, pp. 156-182. Oxford: Oxford University Press.

Kennedy, C. and L. McNally (2005). Scale structure, degree modification, and the semantics of gradable predicates. Language 81(2), 345-381.

Klein, E. (1991). Comparatives. In A. von Stechow and D. Wunderlich (Eds.), Semantik: Ein internationales Handbuch der zeitgenössischen Forschung, pp. 673-691. Berlin: Walter de Gruyter.

Krifka, M. (1998). The origins of telicity. In S. Rothstein (Ed.), Events and Grammar, pp. 197-236. Dordrecht: Kluwer Academic Publishers.

Lewis, D. (1979). Scorekeeping in a language game. Journal of Philosophical Logic 8, 339359.

Matthewson, L. (2004). On the methodology of semantic fieldwork. International Journal of American Linguistics 70, 369-415.

Merchant, J. (2015). How much context is enough? two cases of span-conditioned stem allomorphy. Linguistic Inquiry 46(2), 273-303.

Morzycki, M. (2015). Modification. Cambridge, UK: Cambridge University Press.

Pedersen, W. A. (2015). A scalar analysis of again-ambiguities. Journal of Semantics 32(3), 373-424.

Percus, O. (2006). Antipresuppositions. In A. Ueyama (Ed.), Theoretical and Empirical Studies of Reference and Anaphora: Toward the establishment of generative grammar as an empirical science, pp. 52-73. Tokyo: Japan Society for the Promotion of Science.

Piñón, C. (2008). Verbs of creation. In J. Döllig, T. Heyde-Zybatow, and M. Schäfer (Eds.), Event structures in linguistic form and interpretation, pp. 493-521. Berlin: Walter de Gruyter.

Stanley, J. (2000). Context and logical form. Linguistics and Philosophy 23, 391-434.

Winter, Y. (2006). Closure and telicity across categories. Semantics and Linguistic Theory 16, 329-346. 